\title{
DIVÓRCIO À LA CHILENA: \\ FAMILIA, GÊNERO E CIDADANIA NO CHILE, 1990-2004
}

\author{
Verónica Edith Gómez Urrutia
}

\begin{abstract}
RESUMO
O artigo examina os debates referidos a três reformas legais que tem resultado fundamentais para a configuração legal da família no Chile, acontecidos entre 1990 e 2004. Tomando como base a análise do discurso legislativo, argumento que para tornar o conceito de família mais abrangente, de modo que se reconheça a multiplicidade de realidades que pode representar, foi necessário um longo e complexo processo de negociação política no qual entraram em jogo concepções de gênero, autonomia individual e o questionamento do que constitui uma "boa sociedade". Os resultados desse processo, se bem constituem um avanço em termos de igualdade de gênero, ainda favorecem o modelo de família tradicional-bi-parental, baseada no matrimônio heterossexual - como o tipo de família a ser protegida pelo Estado. Assim, os direitos das mulheres como cidadãs são subordinados aos papéis de gênero tradicionais, já que elas são ainda vistas como responsáveis pelo cuidado de pessoas em situação de vulnerabilidade e pela manutenção da família como espaço de reprodução social. Metodologicamente, o trabalho está baseado em uma análise qualitativa dos registros oficiais dos debates no Parlamento para as três leis examinadas. Essa análise foi complementada com entrevistas em profundidade com legisladores e membros do poder Executivo que participaram dos debates no Congresso Nacional.
\end{abstract}

PALAVRAS-CHAVE: familia; gênero; legislação chilena; direitos da mulher.

\section{INTRODUCCIÓN}

En 2010, el Programa de las Naciones Unidas para el Desarrollo (PNUD) publicó su Informe sobre Desarrollo Humano en Chile, dedicado a examinar la situación de la igualdad de género en el país. Entre otros muchos datos de interés, esta publicación señala que en Chile y para un porcentaje importante de la población encuestada, la principal imagen asociada a la mujer es la de esposa y madre. Según el Informe, la representación más frecuente acerca de la mujer es aquella que la define a partir de los roles que enmarca la familia y la maternidad. Al ser consultados sobre imágenes espontáneamente asociadas a la palabra "mujer", palabras como madre, mamá, dueña de casa o familia forman el grupo más importante de significados $(25 \%)$ expresados por los(as) participantes en el estudio (PNUD, 2010, p. 56). El Informe indica que, en síntesis, la familia sigue siendo el gran referente y la institución que define la identidad de la mujer, tanto para ellas mismas como para los hombres.

El presente trabajo ${ }^{1}$ argumenta que esta identificación se da no sólo en el plano de las representaciones que los(as) sujetos tienen sobre sí mismos(as), sino también en el discurso legislativo a partir del cual se establecen nuevos derechos ciudadanos o se intenta expandir el ejercicio efectivo de derechos ya sancionados a grupos sociales para los cuales este ejercicio estaba limitado - en particular, las mujeres. A pesar de la pluralidad de lazos y formas de convivencia que pueden agruparse bajo el concepto de familia, en el discurso legislativo esta institución se concibe íntimamente asociada al rol de cuidado y socialización infantil realizado mayoritariamente por las mujeres, incluso en el plano de la conceptualización de los derechos de las mujeres en cuanto ciudadanas. Por ello, argumento, la conceptualización de familia predominante en un momento dado en el discurso legislativo presenta un límite - o bien, una posibilidad - para las

\footnotetext{
1 Este artículo fue elaborado como parte del proyecto Fondecyt n. 11080 121, "Modelos de Ciudadanía y perspectiva de género: discursos sobre la ciudadanía femenina en la legislación chilena", financiado por la Comisión Nacional de Investigación Científica y Tecnológica de Chile (Conicyt).
} 
discusiones referidas a la ciudadanía de las mujeres; un límite que está dado, principalmente, por el rol atribuido a las mujeres dentro de la familia como factor de estabilidad social y reproducción de la siguiente generación de ciudadanos(as).

Este artículo está basado en el análisis cualitativo de documentos y entrevistas referidos a la discusión Parlamentaria de tres leyes que representan momentos clave en la discusión de lo que el Parlamento chileno considera "familia" y, dentro de ella, el rol de la mujer, desde el retorno del país a la democracia en 1990: la ley de participación en los gananciales (Ley n. 19335 de septiembre de 1994), que puso en debate la contribución de las mujeres a la construcción del patrimonio familiar a través del trabajo remunerado y no remunerado; la ley de Filiación (19 585, de 1998), que eliminó diferencias legales entre hijos nacidos dentro y fuera de matrimonio, y la ley de Matrimonio Civil de 2004, que introdujo el divorcio vincular en el país. Todas estas iniciativas se discutieron y aprobaron durante el gobierno de la coalición que sucedió a Augusto Pinochet (19731989), la Concertación de Partidos por la Democracia. Dicha coalición, en el poder entre 1990 y 2010, agrupa a partidos de centro-izquierda en torno al partido de centro más numeroso de Chile, la Democracia Cristiana (PDC). Ninguno de estos partidos tenía una agenda explícita en torno a cuestiones de género y familia, aunque los lazos del PDC con la Iglesia Católica y su ideario valórico son bien conocidos (HAAS, 1998; BLOFIELD, 2002). Tanto por su carácter de eje ideológico de la coalición como por el número de escaños ocupados ${ }^{2}$, la postura de $\operatorname{los}($ as) Parlamentarios(as) demócrata-cristianos resultó fundamental para el éxito o fracaso de estas iniciativas. Por su carácter de partido "catch-all" (MAINWARING \& SCULLY, 1995), que representa tendencias ideológicas tanto progresistas como conservadoras, el PDC estableció alianzas tanto con la centro-derecha

\footnotetext{
2 En la historia del siglo XX en Chile, el PDC ha tenido una posición de centro democrático y reformista, formando generalmente alianzas políticas con la izquierda. En el período analizado, la PDC obtuvo entre un 26 y un $20 \%$ de los escaños en la Cámara Baja y entre un 22\% (en las elecciones de 1993 y 2001) y un $29 \%$ (en las elecciones de 1989 y 1997) de los escaños de la Cámara Alta, siendo una de las primeras mayorías en el Congreso chileno.
}

(representada por el partido Renovación Nacional) como con los sectores de centro-izquierda e izquierda dentro de la misma Concertación, sin que en las votaciones se verificara una línea partidaria claramente definida.

El método de análisis escogido fue la identificación de categorías recurrentes en el discurso, que dieran cuenta de representaciones sobre nociones de familia y los roles identificados en ella para hombres y mujeres. Estas categorías fueron definidas a priori con los referentes provistos por la teoría de género, aunque se consideraron también categorías emergentes (PÉREZ SERRANO, 1998). En una segunda etapa, con la ayuda de herramientas computacionales (programa Atlas.ti) se identificaron relaciones y asociaciones entre categorías, que permitieron establecer ideas o argumentos concurrentes, ya sea en términos de reforzarse unos a otros o bien de contradecirse. Ello, con el propósito de reconstruir la estructura general del discurso y, particularmente, los ejes de argumentación que sirvieron como base para la negociación política que permitió que estas leyes fueran finalmente aprobadas. Más de 4000 páginas de discurso legislativo fueron analizadas de esta manera. Este análisis fue complementado con entrevistas en profundidad a nueve legisladores del Congreso Nacional, dos ex Ministras, dos oficiales del Ejecutivo y tres asesores parlamentarios, que fueron seleccionados(as) utilizando como principal criterio el que hubieran estado activamente involucrados en la discusión de las iniciativas legales mencionadas, ya sea a favor o en contra.

Dichas entrevistas permitieron verificar los ejes centrales del discurso y obtener insight respecto de las estrategias que se utilizaron para la construcción de consensos al interior del Parlamento. La construcción de estos consensos y su justificación constituyen el foco principal de este estudio, que se centra en el discurso legislativo, más que en las oportunidades políticas o las estrategias movilizadas por los actores para avanzar posiciones en el Congreso. Ello, porque en la legislación cristalizan una serie de expectativas normativas que definen lo que, desde el Estado, resulta deseable en términos de comportamiento sexual y reproductivo, establecimiento de vínculos familiares y responsabilidad intergeneracional (cuidado de niños y adultos mayores), entre otras, que se tornan vinculantes para todos(as) $\operatorname{los}($ as $)$ 
ciudadanos(as) de un Estado, estableciendo con frecuencia deberes y derechos de ciudadanía diferenciados para hombres y mujeres.

\section{FAMILIA, FAMILIAS Y EL ESTADO}

El concepto de familia no está explícitamente definido en la Constitución de 1980, aprobada bajo el régimen del general Augusto Pinochet. De acuerdo a los registros existentes sobre este proceso, ello obedecería a la intención explícita del legislador de no establecer un tipo jurídico que pudiera resultar excluyente. Así, se reconocería que el concepto de familia como institución cubre una gran diversidad de realidades, tanto desde una mirada histórica como desde la perspectiva de los arreglos familiares que coexisten en una misma sociedad en un período histórico determinado. Si bien hay tipos de arreglos familiares que pueden predominar en una época histórica determinada, la diversidad de ellos parece ser un rasgo clave de la misma (INFANTE \& SUNKEL, 2004; VALENZUELA, TIRONI \& SCULLY, 2006; ARRIAGADA, 2007; VALDÉS, 2007b). La propia definición de lo que constituye una familia, como observan estos autores(as), conjuga una serie de factores variables como los lazos de parentesco, vida en común como proyecto de largo plazo o las tareas que sean atribuidas a este grupo de personas, tales como la reproducción, el cuidado y gratificación emocional, la socialización de los niños(as) y la constitución de redes de apoyo mutuo, cuya articulación está fuertemente influenciada por factores culturales, sociales y económicos.

A pesar de ello, como observan Morley, "cada vez que se menciona la palabra 'familia' seguimos teniendo una fuerte tendencia a concebirla como la familia nuclear tradicional, compuesta por dos adultos y sus hijos dependientes, donde el padre sale a trabajar y la madre permanece en casa" (Morley apud INFANTE \& SUNKEL, 2004, p. 39). Y a pesar de que este tipo de familia ha representado proporciones variables de los arreglos familiares en la historia de Chile (a veces ni siquiera mayoritaria), esta imagen tradicional de familia conserva gran parte de su fuerza política e ideológica, como observan los mismos autores. En este contexto, una hipótesis central de este trabajo es que, a pesar de la naturaleza dinámica de la institución familiar, un factor constante es el rol pivotal de la mujer como articuladora de esta red de apoyo de la reproducción, tanto biológica como de la vida cotidiana y en la dimensión de los afectos. Más aún, si bien la legislación no ha definido explícitamente lo que constituya una familia, sí le ha dado forma jurídica a los roles dentro de ella, a través del establecimiento de derechos y deberes entre parejas, padres e hijos u otros parientes consanguíneos, que se refieren tanto a cuestiones de autonomía individual y protección social como a temas patrimoniales. Para el caso chileno Karin Rosemblatt (2000) y Ximena Valdés (2007b) han documentado como parte importante de la conformación de los incipientes estados de bienestar en América Latina a partir de las primeras décadas del siglo XX estuvo basado en la idea de la unidad familiar donde primaba la división tradicional del trabajo entre hombres y mujeres, donde ellos eran responsables de la provisión del sustento económico y ellas del trabajo doméstico, el cuidado y la crianza de hijos e hijas. Así, desde el punto de vista de la protección social las familias se vinculaban con el Estado a través del trabajo remunerado masculino, que se concebía como un "salario familiar" cuyo monto debía contemplar no sólo al trabajador, sino también a la esposa e hijos dependientes del mismo (idem, p. 108). Con ello, el trabajo doméstico y de cuidado quedó invisibilizado y subsumido en el ámbito de lo privado, sin que se lo considerase una actividad económica relevante para la distribución de beneficios sociales vinculados a la condición de ciudadanía, como ocurrió con el trabajo asalariado. El cuidado de niños, ancianos $\mathrm{y}$ enfermos ha sido tradicionalmente visto como una actividad propiamente femenina, una extensión "natural" de las tareas asociadas a la maternidad y a la esfera doméstica y, por lo tanto, algo que las familias producen para sí mismas.

La familia conjuga así lo biológico con lo social y lo político. No obstante, como Martha Nussbaum ha observado, las miradas políticas sobre la familia, tanto liberales como no liberales, frecuentemente asumen como dadas tres características de esta institución que son en realidad productos socio-políticos: (i) la fundamentación biológica de la familia, disminuyendo la importancia del papel que la tradición, la religión e incluso la ley tienen en su constitución; (ii) su naturaleza "privada", como opuesta a la esfera pública, desdibujando la relación entre ambas y la convencionalidad de definiciones respecto de lo público y lo privado, y (iii) el rol de las mujeres como socializadoras y cuidadoras 
(NUSSBAUM, 2000, p. 252). El feminismo y la teoría de género han hecho un aporte central al poner en cuestión la naturalización de roles al interior de familia y al incorporar la dimensión del poder dentro de las definiciones de familia como un eje clave para entender su forma de funcionamiento interno (VALDÉS, 1998; MONTAÑO, 2007), así como la inequidad de género al interior de la misma.

Para el caso de la concepción esencialista de la familia como entidad "natural", tal vez uno de los ejemplos más claros de esta juridización de roles vistos como naturales sea la relativa incapacidad legal en la cual quedaba la mujer chilena al momento de contraer matrimonio (bajo el régimen de sociedad conyugal) hasta 1989 , año en que se modificó el Código Civil ${ }^{3}$ para - entre otras reformas - derogar el concepto de "potestad marital", que daba al marido derechos sobre la persona y bienes de su cónyuge, dar plena capacidad a la mujer casada en sociedad conyugal (cuyo administrador de facto sigue siendo, sin embargo, el marido) y permitirle ser jurídicamente responsable. La reforma equiparó también a ambos cónyuges en materia de guardas, manteniéndose la posibilidad de que la mujer se excusara de servirlas, pues "la Comisión, para mantener esta causal de excusa, consideró que siempre el papel fundamental de la mujer es el hogar" (ROZAS, 1989, p. 101), por lo cual se prefirió limitar su participación en estas actividades.

Ecos de estos argumentos se escucharon en 1991, cuando el poder Ejecutivo - bajo la administración del DC Patricio Aylwin Patricio Aylwin (1990-1994) - propuso el proyecto de ley por el cual se modificaba el régimen patrimonial del matrimonio, con un Mensaje presidencial que planteaba: "El Gobierno considera un deber ineludible proponer modificaciones legales que permitan la efectiva vigencia, dentro del ordenamiento jurídico chileno, del principio constitucional de igualdad ante la ley referido a la mujer, con la finalidad de establecer el completo respeto a su dignidad ciudadana y proteger, de este modo, la estabilidad de la familia" (CHILE. CONGRESO NACIONAL DE CHILE, 1998a, p. 72; el subrayado es mío). El nuevo régimen

\footnotetext{
3 El código civil chileno, basado en el Napoleónico, fue modificado en estas materias recién un año antes del retorno del país a la democracia, mediante la Ley n. 18802.
}

procuraba dar a las mujeres mayores derechos en la administración de la propiedad que aportan a la familia y la posibilidad relativa de compensar las oportunidades económicas no aprovechadas por privilegiar el trabajo de cuidado. Ello, porque permite que cada cónyuge administre sus bienes de manera independiente. Sin embargo, las ganancias producidas por los bienes durante la vigencia del matrimonio se dividen por partes iguales en caso de término del mismo.

El proyecto original procuraba hacer efectiva la capacidad nominal que la reforma de 1989 daba a las mujeres, haciendo de la participación en los gananciales el régimen conyugal por defecto, y recibió el apoyo de los sectores más progresistas de la Concertación, especialmente el Partido por la Democracia (PPD, centro-izquierda) y el Partido Socialista. Por el contrario, un grupo importante de Parlamentarios(as), mayoritariamente pertenecientes al centro y derecha del espectro político chileno (HAAS, 1998) se opuso al proyecto con el argumento de que la sociedad conyugal era el régimen que más se adecuaba a la comunidad de intereses representada por el matrimonio y la familia y la que mejor protegía a la mujer dada su condición de responsable por el cuidado del hogar y de los hijos, aunque se aceptó incluir el régimen de participación en los gananciales como una opción.

En efecto, una mirada a la sociedad chilena de los noventa muestra que las chilenas se dedicaban principalmente al hogar. De acuerdo al Censo de 1992 , un $28 \%$ de las mujeres chilenas tenía trabajo remunerado ese año. Aunque no contamos con datos de la época que exploren las razones que explican la baja participación laboral de las chilenas, datos más recientes sugieren la persistencia de pautas culturales basadas en la división sexual del trabajo. Según los datos de la encuesta de Caracterización Socioeconómica Nacional (Casen), de 2003, el hecho de tener que permanecer en casa para atender las necesidades domésticas constituye el $50 \%$ de las motivaciones de las mujeres para permanecer fuera del mercado laboral. Entre los hombres, este motivo no se menciona (CHILE. MIDEPLAN, 2003, p. 19). Los datos aportados por Milosavljevic (2007) sugieren que la presencia de hijos(as) menores de seis años constituye un factor fundamental para determinar el que las mujeres tengan el trabajo doméstico y/o de cuidado, no remunerado, como actividad principal o única: en promedio, mientras el 23,8\% 
de mujeres sin hijos(as) declara estar en esta situación, en el caso de quienes tienen dos o más hijos, la proporción de mujeres que declara estar dedicada al trabajo doméstico en forma exclusiva o principal sube a casi $40 \%$. Otros estudios, como los realizados por Mauro y Yáñez (2005) y Todaro (2006) muestran que la inserción laboral de las mujeres chilenas está fuertemente condicionada por las responsabilidades familiares: ellas tienden a preferir el trabajo a tiempo parcial o a domicilio y a presentar trayectorias laborales interrumpidas por el nacimiento de hijos e hijas.

El régimen de sociedad conyugal asume esta división sexual del trabajo - productivo, remunerado para los varones, reproductivo y no remunerado para las mujeres -, colocando a estas últimas en una relación de subordinación frente a su cónyuge, ya que la sociedad es siempre administrada por el marido. Ello refleja la valoración inferior del aporte representado por el trabajo doméstico y de cuidado de infantes y otras personas en situación de dependencia (ancianos y enfermos, por ejemplo) al bienestar de la familia y de la sociedad misma. Como observa Fineman (2004), el trabajo de cuidar de otros(as) permanece sub-valorado e invisible en la medida en que se lo considera un bien que las familias proveen para sí mismas, ignorando la contribución basal que hace a la manutención de toda la sociedad. La separación de bienes ignora también este hecho, por cuanto falla en reconocer la desigualdad de condiciones en que las mujeres entran al mercado laboral y la persistencia de pautas culturales que implican un nivel menor de remuneraciones por el mismo trabajo - diferencia que en Chile puede llegar al 33\% - y que les asignan el trabajo de cuidado como responsabilidad casi exclusiva (PNUD, 2010).

El régimen de participación en los gananciales, si bien introduce mejoras en términos de reconocer el aporte del trabajo doméstico y de cuidado, sigue considerándolo una problema "privado", propio de las familias. Por lo tanto, las posibilidades que las mujeres tienen de incrementar su propio patrimonio a través del trabajo remunerado o de ampliar sus oportunidades de vida fuera del hogar siguen condicionadas por este hecho. El cambio legislativo no fue acompañado de una política pública que abandone la idea de que el cuidado es una responsabilidad radicada en la familia. En ese contexto, la provisión pública es asumida como un complemento para aquellos hogares que no puedan resolverlo por sí mismos. Por ejemplo, de acuerdo con cifras del Ministerio de Educación, la cobertura de la educación preescolar pública (población menor de seis años) era de sólo 16,6\% en 1990. Según la encuesta Casen de ese año, la oferta de educación preescolar-pública y privada -, dio cobertura al 20,9\% de esta población en 1990. Diez años más tarde, en 2000, la cobertura pública de educación pre-escolar era de $26,5 \%$, según el Ministerio de Educación (CHILE. MINISTERIO DE EDUCACIÓN, 2002) y la oferta total llegaba al $32,5 \%$ - esto es, un avance de casi 12 puntos porcentuales en una década. Para 2009, la cobertura total era de $37,5 \%{ }^{4}$. Sin embargo, junto con la expansión se observa una fuerte segmentación en el acceso a este servicio por parte de hogares con diferentes niveles de ingreso: la tasa de cobertura total para quienes están dentro del $20 \%$ de los hogares más ricos prácticamente duplica la tasa correspondiente al $20 \%$ de los hogares más pobres (CHILE. MIDEPLAN, 2009).

Estas cifras explicarían, en una medida importante, la persistencia en Chile de bajas tasas de participación laboral femenina, especialmente entre las mujeres de menores recursos (SELAMÉ, 2004) y la manutención de una estructura de inequidad de género en acceso al empleo y salarios. En este escenario, la introducción del régimen de participación en los gananciales tiene pocas posibilidades de impactar la distribución de oportunidades de vida por género mientras el trabajo doméstico y de cuidado no sea asumido como una tarea que no es sólo de interés y beneficio de las propias familias, sino también vital para la existencia de la sociedad ${ }^{5}$. Martha Fineman (2004) y Paul Kershaw (2006) han argumentado

4 Cifra basada en la tasa neta de asistencia preescolar (número total de alumnos de 0 a 5 años que asisten a preescolar por sobre la población de cero a cinco años). La tasa bruta de asistencia preescolar (número total de alumnos que asisten a preescolar por sobre la población de cero a cinco años) llegó a 45\% (CHILE. MIDEPLAN, 2009).

5 Posteriores intentos por reunir apoyo político para reformar la sociedad conyugal tampoco han sido exitosos (URRUTIA, 2010a). Paradójicamente, los datos del Registro Civil muestran que en la actualidad la mayoría de los matrimonios siguen celebrándose en la modalidad de sociedad conyugal: en 2000, de un total de 67397 matrimonios, 45 $454(67 \%)$ fueron celebrados bajo este régimen, 19960 (29\%) con separación de bienes y sólo 1983 (2,9\%) como participación en los gananciales. Diez años más tarde, en 
que la privatización de este tipo de trabajo, basada en la idea de que es una cuestión privada que concierne sólo a la familia, ha ocultado la medida en que el trabajo doméstico y de cuidado contribuye a hacer posibles otras actividades que sí son reconocidas como cruciales para el bienestar social, como el trabajo remunerado, la defensa de las fronteras nacionales o la generación de bienes colectivos.

El nuevo régimen patrimonial, la participación en los gananciales, fue aprobado después de un debate parlamentario relativamente breve (1991 a 1994), ya que no alteró la estructura fundamental de la familia tradicional ni la distribución de las tareas de cuidado. En otras palabras, no requirió negociar el sentido último del término "familia". No obstante, marcó un hito en términos de abrir la discusión sobre la situación de la mujer en el matrimonio y la familia. Ello, porque expone la forma en que el Estado, a través de las leyes y las políticas públicas, conforma relaciones de poder y determina el acceso al patrimonio de cada uno de los(as) integrantes del grupo familiar, poniendo en cuestión la división entre las familias como entidades puramente "privadas". Si bien la familia constituye una dimensión clave en la vida y los afectos personales de los individuos, resulta relevante señalar que, como indican autoras como Nussbaum (2000) y Vogel (1998), el Estado no sólo sanciona jurídicamente formas de relación pre-existentes, incorporándolas a un ordenamiento jurídico dado, sino que moldea activamente a través de la ley y la política pública las formas de familia que se consideran más apropiadas al tipo de sociedad o nación que se desea construir - y también, como señala Fineman (2004), para perpetuar los valores que se consideran fundacionales en una sociedad.

Para el caso de Chile, Macarena Ponce de León, Francisca Rengifo y Sol Serrano (2006) y Karin Rosemblatt (2000) han documentado como en diversos momentos de la historia independiente del país un modelo de familia "moral y pedagógica" (PONCE DE LEÓN, RENGIFO \& SERRANO, 2006) y "bien constituida" (ROSEMBLATT, 2000)

2010, estas proporciones se mantienen: $54 \%$ para la sociedad conyugal, $43 \%$ para la separación de bienes y sólo $2,4 \%$ para la participación en los gananciales. Cifras obtenidas del sitio del Registro Civil de Chile (CHILE. REGISTRO CIVIL, 2011). ha sido considerado como base para la estabilidad social. Ponce de León, Francisca Rengifo y Sol Serrano señalan: "La familia como objeto de las bondades del orden social o como culpable de su desintegración, la familia como un modelo normativo que la sociedad no logra hacer completamente suyo, la familia como elemento central de distintos proyectos sociales, ha ocupado a las elites desde la formación misma del Estado Nacional" (PONCE DE LEÓN, RENGIFO \& SERRANO, 2006, p. 43).

La idea de las familias como entidades privadas, sin embargo, se desdibuja nuevamente cuando se considera el importante papel que desempeñan reconocido implícitamente por el Estado - en la organización de una sociedad y en la consecución de una idea de bien común o de sociedad "bien ordenada" (orderly society, como plantea Vogel (1998); véase también Jelin (2007)) ${ }^{6}$. De los ámbitos o funciones que se consideran propias de la familia (INFANTE \& SUNKEL, 2004; VALENZUELA, TIRONI \& SCULLY, 2006) reproducción (biológica), socialización, protección y refugio emocionales y fortalecimiento de lazos comunales -, las dos primeras son clave para la continuidad o cambio de una sociedad. Y todas ellas tienen un elemento de género importante, pues en nuestro orden cultural las mujeres son las principales (si no únicas) responsables de las labores domésticas y de cuidado, de la socialización de niños y niñas y de la protección de la dimensión afectiva de la vida cotidiana. Ello, de manera paralela a la adquisición de nuevos roles. A medida que aumentan los niveles de educación entre las mujeres - que hoy asisten a la educación superior en un porcentaje levemente mayor que los hombres - ellas ingresan en mayores números al mercado laboral. En 2010 el porcentaje de mujeres que trabaja remuneradamente fuera del hogar llega al 44\%, según cifras del Instituto Nacional de Estadísticas (INE). Este porcentaje es aún bajo comparado con otros países con similares tasas de fecundidad (1,9 hijos por mujer al año 2009) e

\footnotetext{
6 Aunque no la defina, la propia Constitución chilena de 1980 establece en su capítulo I que "La familia es el núcleo fundamental de la sociedad" y que "Es deber del Estado resguardar la seguridad nacional, dar protección a la población y a la familia, propender al fortalecimiento de ésta, promover la integración armónica de todos los sectores de la Nación y asegurar el derecho de las personas a participar con igualdad de oportunidades en la vida nacional".
} 
ingreso per capita. En contraste, la cifra de mujeres que declaran ser jefas de hogar llega al 33\%. Gran parte de estos hogares con jefatura femenina son monoparentales, de acuerdo a las cifras de la Encuesta Casen de 2009, revelando que cada vez más mujeres asumen el rol de proveedor económico $y$ de cuidado.

En este escenario, tras el retorno de Chile a la democracia en 1990 el Parlamento chileno enfrentó el desafío de legislar frente a nuevas condiciones sociales, impulsado tanto por movimientos sociales como por individuos que buscaban actualizar una legislación que parecía poco apta para las nuevas condiciones sociales y, particularmente, para lograr una mayor igualdad en las relaciones de género. Dentro de éstos se encontraban Parlamentarios(as) $\mathrm{y}$ oficiales del poder Ejecutivo que, en ausencia de una política partidaria explícita sobre temas de género y familia, promovieron iniciativas legales en estas materias. En el plano internacional, a partir de 1994, con la Conferencia Internacional sobre Población y Desarrollo, el concepto demográfico de familia se había ido debilitando para dar paso a una noción basada en los derechos de cada uno de los individuos miembros del grupo familiar (MONTAÑO, 2007, p. 79). Dentro de este proceso, la promulgación de una ley contra la violencia intrafamiliar (Ley n. 19325 de 1994) ${ }^{7}$ fue un hito mayor en términos de extender la noción de derechos - en este caso, a la integridad física y psicológica - al dominio tradicionalmente privado de las relaciones familiares. Como documentan Araujo, Guzmán y Mauro (2000) la propuesta de ley original, basada en la noción del derecho de las mujeres a una vida libre de violencia y a la protección del Estado dentro de la familia, fue cediendo paso a una interpretación que privilegiaba la protección de la familia como deber del Estado. No obstante, para la mayoría de los(as) Parlamentarios(as) y miembros del poder Ejecutivo entrevistados para este estudio, ésta fue la primera gran apertura legislativa para debatir la concepción de "familia" a la que debía protegerse y la tensión que ello podía generar con los derechos individuales de cada uno de sus miembros, en especial los más vulnerables.

\footnotetext{
7 Esta ley fue reformulada en 2005 (Ley n. 20 066). Para una excelente discusión del proceso por el cual la primera ley sobre violencia intrafamiliar llegó a promulgarse en Chile, véase Araújo, Guzmán y Mauro (2000).
}

Con todo, las tareas pendientes eran múltiples. A principios de los noventa Chile no contaba con una ley de divorcio vincular, seguían existiendo importantes diferencias legales entre hijos e hijas nacidos dentro y fuera de matrimonio, el aporte económico de las mujeres al patrimonio familiar estaba escasamente reconocido y la regulación de uniones consensuales, hetero $\mathrm{u}$ homosexuales ${ }^{8}$ no había ingresado a la agenda política. El orden legal existente dejaba a las mujeres y sus hijos(as) particularmente desprotegidos en caso de abandono o separación de hecho, o bien ante la eventualidad de que un hijo(a) nacido fuera de matrimonio no fuera reconocido por el padre. Éste último caso en particular, el de la filiación, será examinado en la sección siguiente.

\section{FAMILIA, ¿PARA QUIÉN?: LA LEY DE FILIACIÓN}

En Enero de 1997, en el centro de Santiago pequeños grupos de ciudadanos - principalmente mujeres - con pancartas rondaban el Ministerio de Justicia, demandando la pronta aprobación de la Ley de Filiación. Esta iniciativa también fue propuesta por el poder Ejecutivo bajo la administración del DC Patricio Aylwin, quien la presentó al Parlamento en 1993, meses antes del término de su mandato. El objetivo de la propuesta era eliminar las diferencias legales entre hijos(as) nacidos dentro y fuera de matrimonio, sobre la base del principio de igualdad garantizado por la Constitución (CHILE, 1993) y la responsabilidad paterna frente a la prole. Se eliminaba así la distinción entre hijos(as) legítimos, naturales e ilegítimos y los diferentes derechos asociados a cada una de estas condiciones. En el momento de ingresar la ley al Parlamento, en Chile más del $40 \%$ de los nacimientos tenía lugar fuera del matrimonio, y una proporción importante de éstos ocurría en el contexto de relaciones de pareja

\footnotetext{
8 La cuestión de las uniones civiles entre personas del mismo sexo sólo entró en la agenda política chilena muy recientemente. El 10 de Julio de 2003 ingresó al Parlamento un proyecto de ley sobre Fomento de la no discriminación y contrato de unión civil entre personas del mismo sexo (Boletín 3283-18), que fue archivado en Agosto de 2009 tras haber pasado por la Comisión de Familia y sin haber llegado al Plenario. Otro proyecto de la misma naturaleza, presentado en Marzo de 2008 (Boletín 5774-18), fue archivado apenas dos años después, en Junio de 2010, en las mismas circunstancias.
} 
estable o uniones consensuales 9.

Esta situación no era inédita en Chile. Autoras como Valdés (2007a) y Ponce de León, Rengifo y Serrano (2006) señalan que la prevalencia de la ilegitimidad fue particularmente aguda en el país en la segunda mitad del siglo XIX y principios del $\mathrm{XX}$, en el contexto de rápido cambio social, migración campo-ciudad y la introducción del matrimonio civil, que alteraron los patrones de constitución familiar vigentes hasta entonces. De acuerdo con las autoras, la proporción de niños ilegítimos nacidos en Chile entre 1848 y 1916 aumentó desde un quinto del total de los recién nacidos a más de un tercio, con Santiago - foco de atracción principal de los migrantes del mundo rural y del norte minero- presentando índices aún mayores (idem, p. 68). El incipiente Estado de Bienestar surgido a partir de la década de 1920 tomaría una serie de medidas para subsanar esta situación e incentivar el matrimonio legal, la constitución de varones que fueran proveedores confiables y mujeres que fueran buenas madres y amas de casa, cuidadoras apropiadas del "capital humano" de la nación (ROSEMBLATT, 2000). Todas estas medidas suponían el ejercicio de la sexualidad "legítima" en el marco del matrimonio legal, por cuanto sólo los hijos(as) nacidos en esa condición podían ser sujetos de derechos desde el punto de vista de los beneficios que los padres recibían del Estado - por ejemplo, la asignación familiar, que consistía en dinero extra para los varones casados y por cada hijo legítimo nacido. Este beneficio, como se observó más arriba, suponía que la responsabilidad económica por la familia recaía exclusivamente en el varón, cuyo salario debía ser suficiente para mantener a una esposa e hijos (llamadas "cargas" para estos efectos) y evitar que las mujeres debieran salir a trabajar. Así, quien se vinculaba con el Estado era el jefe de hogar: mujer e hijos lo hacían a través de los beneficios que el salario masculino llevaba aparejados.

La estrecha vinculación entre matrimonio, familia y Estado no es, por supuesto, nueva. Con el tiempo, las prácticas - si no las leyes -

\footnotetext{
9 Según cifras del Servicio Nacional de la Mujer (Sernam), en 1996, 110000 (42\%) niños fueron inscritos como ilegítimos, el $75 \%$ reconocidos por ambos padres y concebidos en uniones estables sin formalizar (CHILE. SERNAM, 1996).
}

comenzaron a permitir que los hijos naturales (nacidos fuera de matrimonio, pero reconocidos por ambos padres) fueran sujetos de algunos beneficios estatales (VALDÉS, 2007b). No obstante, a principios de los noventa el matrimonio como base de la unión de pareja y la procreación comenzaba nuevamente a desdibujarse (INFANTE \& SUNKEL, 2004; ARRIAGADA, 2007). La legislación chilena, en tanto, mantenía como modelo implícito de familia la biparental, sancionada por matrimonio, con roles de género claramente definidos. Varios proyectos parlamentarios habían intentado abordar la cuestión del status legal de los hijos nacidos fuera del matrimonio desde 1990 e incluso con anterioridad $^{10}$, pero la discusión no llegó a la Sala hasta que el poder Ejecutivo refundió estas iniciativas en una nueva propuesta ${ }^{11}$, proponiendo la igualdad de los hijos y la consagración del principio de la libre investigación de la paternidad y de la maternidad.

La propuesta comenzó a discutirse después de las elecciones de 1993, en las cuales resultó electo el también DC Eduardo Frei Ruiz-Tagle para el periodo 1994-2000 con una amplia mayoría concertacionista en el Congreso. La propuesta fue bien recibida al interior de la coalición en el poder, aunque despertó oposición en algunos sectores del ala conservadora de la Democracia Cristiana (PDC), así como también en parlamentarios a la derecha del espectro político - Renovación Nacional (RN) y la Unión Democrática

10 En 1972 ya se había presentado un proyecto de ley que terminaba con las diferencias entre hijos legítimos e ilegítimos, según hubieran nacido o no dentro del matrimonio. El artículo 12 del texto legalizaba la convivencia entre un hombre y una mujer que hubieran cohabitado durante dos o más años sin estar casados. La iniciativa legal fue suspendida por el golpe de Estado de 1973 y el subsecuente cierre del Parlamento.

11 El proyecto de ley del poder Ejecutivo recogió planteamientos presentados en mociones presentadas por los diputados Laura Rodríguez (Partido Humanista-Verde), Víctor Barrueto (Partido por la Democracia), Vladislav Kuzmicic (independiente de izquierda), Octavio Jara y Adriana Muñoz (ambos del Partido por la Democracia), sobre trato igualitario para todos los hijos. También incorporó las pruebas de ADN obligatorias como reconocimiento paterno, propuestas por los diputados Sergio Aguiló y Jaime Naranjo (ambos del Partido Socialista), y la ampliación de la paternidad, presentada por el diputado PDC Hernán Bosselin. 
Independiente (UDI). La oposición al proyecto se basaba en la idea de que igualar las condiciones de los hijos, sea cual fuere la situación legal de los padres al momento del nacimiento, socavaba las bases de la familia al disminuir la importancia del matrimonio como lugar legítimo de procreación. Asimismo, el proyecto exponía a los varones a acusaciones de paternidad infundadas y obligaba a las familias a compartir el patrimonio conseguido por ellos con personas con las que podían no tener ningún lazo afectivo o identitario, según sus detractores. Había, también, una reticencia a colocar concepciones de familia en la discusión, pues eso dejaba espacio para la necesidad de reconocer que no había una familia, sino una multiplicidad de arreglos familiares cuyos miembros tenían una relación diferenciada con el Estado desde el punto de vista de los derechos ${ }^{12}$. Esto ya había sido señalado en el Informe elaborado por la Comisión Nacional de la Familia en 1993, organismo creado especialmente por el Gobierno de Aylwin para hacer recomendaciones para el diseño de políticas públicas sobre la materia. Dicho informe reconoció la diversidad de familias existente en Chile y planteó la necesidad de reconocer formas de asociación familiar no basadas en el matrimonio - por ejemplo, las uniones consensuales (INFANTE \& SUNKEL, 2004, p. 40-41).

El proyecto de ley de filiación colocaba, de un cierto modo, un signo de interrogación respecto de la estructura y el propósito de la familia. En la medida en que distinguía jurídicamente entre hijos legítimos, ilegítimos y naturales, la legislación vigente hasta 1998 no reconocía consistentemente el fundamento biológico (parentesco), pues priorizaba el lazo jurídico antes que la posibilidad de que se investigara la posible paternidad. El reconocimiento de ésta quedaba a voluntad del hombre, privilegiando el derecho de éste a la honra y a la privacidad por sobre el derecho de los hijos a conocer su verdadero origen y el de las madres a compartir con los padres la responsabilidad por la crianza, tanto en lo económico como en la

12 Entrevistas personales con Josefina Bilbao M., Ministra del Servicio Nacional de la Mujer (Sernam) para el periodo 1994-2000, Santiago de Chile, 25 de Marzo de 2010; Fanny Pollarolo, Diputada (Partido Socialista), Santiago de Chile, 25 de Marzo 2010, y Leonor Etcheberry, Asesora Jurídica y co-autora del proyecto original, Santiago de Chile, 24 de Septiembre de 2010. provisión de cuidado. Por otra parte, también cuestionaba el propósito de la familia como lugar de comunidad de intereses y desarrollo personal e - incluso - la validez del ideal normativo para la población, dado el hecho sociológico del constante aumento en el número de niños(a) nacidos fuera de matrimonio ${ }^{13}$. Finalmente, resaltaba el papel atribuido a la familia como unidad económica y base para la reproducción de un cierto orden patrimonial, mediante la discusión sobre las obligaciones de alimentos y los derechos de herencia.

Al examinar los registros de los debates parlamentarios para esta ley, tres categorías o marcos interpretativos aparecen consistentemente en la discusión, tanto en la Cámara como en el Senado: la igualdad jurídica, la protección a la familia como base para la estabilidad social y los argumentos de orden patrimonial. El primero, que fuera la base del proyecto original, constituyó una base de negociación amplia, pues se trataba de un principio legitimado (aunque no siempre aplicado) que además estaba consagrado por la Constitución chilena y por diversos tratados internacionales suscritos por Chile, y es el más frecuentemente invocado. No obstante esta idea - la igualdad de las personas - entraba en conflicto con la idea de familia como institución que debía ser preservada de acuerdo a un modelo normativo que se veía como base para la estabilidad social y dentro del cual resultaba difícil instalar la noción de libertades y derechos como aplicadas al ámbito personal ${ }^{14}$. Como señala Fineman (2004), examinar la idea de familia implica revisar, también, los arreglos sociales vigentes para las funciones que se consideran propias de la misma-particularmente,

13 Esta tendencia aún se mantiene: según los datos del Registro Civil, el porcentaje de hijos(as) nacidos fuera de matrimonio ha registrado un aumento constante durante la década, llegando al 68\% en 2010 (CHILE. REGISTRO CIVIL, 2011).

14 Entrevistas personales con Mariana Aylwin, Diputada Democracia Cristiana, Santiago de Chile, 13 de Enero de 2010; Josefina Bilbao M., Ministra del Sernam, para el periodo 1994-2000, Santiago de Chile, 25 de Marzo de 2010; Fanny Pollarolo, Diputada (Partido Socialista), Santiago de Chile, 25 de Marzo 2010; María Antonieta Saa, Diputada (Partido por la Democracia), Santiago de Chile, 30 de Abril de 2010); Adriana Muñoz, Diputada (Partido por la Democracia), Santiago de Chile, 6 de Septiembre de 2010; Andrés Zaldívar, Senador (Democracia Cristiana), Talca, 10 de Julio de 2010. 
la responsabilidad por el trabajo reproductivo, tanto en lo biológico como en lo social. Eludiendo esta idea, parte importante del debate se centró en los efectos de la iniciativa legal en términos de fortalecer o debilitar a la familia y son frecuentes las referencias al bien común asociadas a la manutención de las formas tradicionales de hacer familia. En el análisis de los debates parlamentarios, la idea de igualdad como no-discriminación aparece regularmente matizada por la idea de que la igualdad dentro de la familia está sujeta a otros parámetros. Un ejemplo de este marco interpretativo lo dan los extractos siguientes: "El diferente tratamiento de los hijos, en cuanto a su posición familiar [legítimos e ilegítimos], procede, precisamente, del precepto que nuestra propia Constitución consagra en su artículo primero, al reconocer que 'La familia es el núcleo fundamental de la sociedad', agregando a renglón seguido, que es deber del Estado darle protección y propender a su fortalecimiento" (Diputado, hombre, partido de centro-derecha. Historia de la Ley n. 19 585, p. 170. Legislatura 334, sesión 44 del 23 de Enero de 1997). "Cuando entran en colisión derechos de los hijos o descendientes surgidos en el seno de esa familia formada consciente y regularmente, con los hijos surgidos de relaciones no formalizadas jurídicamente [...] No nos hallamos ante un problema de aplicación del principio de igualdad, sino ante uno de mayor hondura y complejidad: qué concepción de la familia, como institución social [...] será recogida y reflejada en los textos legales" (Senador, hombre, partido de centro-derecha. Historia de la Ley n. 19 585, p. 609. Legislatura 334, sesión 30 del 05 de Marzo de 1997).

Este segundo marco interpretativo - la defensa de la familia tradicional como base para la estabilidad social - intentó ser conciliado con el primero por sus proponentes a través de la noción de que la igualdad como no-discriminación se aplicaba cuando la distinción se hacía sobre la base de un atributo irrelevante - como el color de la piel - y no sobre uno socialmente válido, como lo sería el haber nacido dentro o fuera del matrimonio. Como observó una Senadora: "[N]o puede estimarse que la existencia o inexistencia del matrimonio constituya una discriminación arbitraria que permita o no distinguir en la calidad de los hijos. [...] El legislador puede reconocer beneficios pecuniarios, pero no puede convertir, por arte de magia, en iguales situaciones jurídicas que son desiguales en sí y por esencia" (Senadora, mujer, partido de centro-derecha. Historia de la Ley n. 19 585, p. 622. Legislatura 334, sesión 30 del 05 de Marzo de 1997).

Esta concepción enfatizaba el carácter prepolítico de la familia, señalando que no se trataba de un "mero contrato", sino de una asociación "natural" basada en el matrimonio. Esta última idea aparece frecuentemente relacionada con la noción de derechos patrimoniales asociados a la condición de legitimidad" o de ser "hijo(a) matrimonial": si el matrimonio era la base de la familia "legítima", era lógico suponer que el patrimonio construido sólo podía ser compartido entre los miembros de dicha familia. Sin embargo, la concepción de la familia como entidad natural no permitía refutar la demanda por la libre investigación de la paternidad y la maternidad contenida en el proyecto, aspecto de la propuesta legal que volvió a poner en el centro de la discusión la tensión entre individuos y sus libertades personales y la familia como institución. Para quienes buscaban la aprobación de la ley, mantener derechos patrimoniales y de otra naturaleza diferenciados en función de la demarcación jurídica (el matrimonio) de un acto biológico (la concepción) significaba anteponer el acto jurídico a los derechos de las personas en aras de una determinada idea de orden público y social que no era consistente con el principio de igualdad. Como expresaron representantes en la Cámara Alta: "El núcleo fundamental de la sociedad se vigorizará sólo si se funda en la verdad, la igualdad, la fidelidad matrimonial y un ejercicio responsable de la sexualidad y la paternidad [...]. No es posible aducir como fin la defensa de la familia, para emplear un medio ilegítimo. Las personas no pueden ni deben ser tratadas como un simple medio para la realización de determinados fines, por muy loables que éstos sean" (Senador, hombre, partido de izquierda. Historia de la Ley n. 19 585, p. 581. Legislatura 334, sesión 24 del 14 de Enero de 1997). "Se ha dicho que la igualdad de los hijos, nacidos o no dentro del matrimonio, debilita a la familia legalmente constituida. [...] [Pero] no se puede defender una institución legal perjudicando a terceros inocentes por la irresponsabilidad cometida [por sus progenitores]" (Senadora, 
mujer, partido de centro-izquierda. Historia de la Ley n. 19 585, p. 643. Legislatura 334, sesión 30 del 05 de Marzo de 1997).

La demanda por la libre investigación de la paternidad y los aspectos patrimoniales asociados a ella también pusieron en evidencia las desigualdades de género sancionadas por la defensa de la familia reconocida sólo a través del matrimonio, ya que dejaba a las mujeres que tuvieran hijos(as) nacidos fuera del vínculo legal sujetas a la voluntariedad del reconocimiento de las obligaciones asociadas a la paternidad, como hemos señalado antes ${ }^{15}$. Entre sus disposiciones, el proyecto de Ley de Filiación también mejoraba los derechos de herencia del cónyuge sobreviviente (cuestión que, por razones demográficas, posiblemente beneficiaría mayormente a mujeres), lo cual contrastaba con la carencia de derechos de las mujeres en relaciones extramatrimoniales y su exclusiva responsabilidad por hijos e hijas nacidos en esa condición. Sin embargo, esta línea de argumentación aparece con poca frecuencia en los debates. Mucho más relevante como argumento resultó, en este sentido, la noción de que los hijos e hijas no deberían ser responsabilizados y sancionados por la conducta de sus progenitores, frecuentemente esgrimido en los debates, y el derecho de toda persona a conocer sus orígenes. Fue precisamente el primero de estos argumentos el que permitió vencer las resistencias al interior de la Concertación, obteniendo el apoyo de los(as) Parlamentarios del PDC e incluso de algunos representantes del Partido Renovación Nacional (centro derecha). En las últimas etapas del debate, a fines de 1997, los(as) Parlamentarios(as) enfrentaban las elecciones de Diciembre de ese año y una creciente presión ciudadana por la aprobación de la ley.

Entre los(as) entrevistados(as) para este estudio hay consenso en que los aspectos patrimoniales del nuevo régimen de filiación fueron un obstáculo importante para la aprobación de la iniciativa legal pero que, en general, este tipo de argumento no fue planteado abiertamente, pues carecía de una base amplia que sustentara la negociación en el

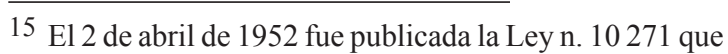
permite la investigación de la paternidad, pero en forma restringida, por causales muy difíciles de aplicar en la práctica y que dependían de la voluntad discrecional del padre, lo cual la hizo poco efectiva.
Congreso. Era, de hecho, un punto importante para representantes de la derecha tradicional, particularmente miembros del Partido Unión Democrática Independiente (UDI). Una situación similar ocurrió con los derechos de las mujeres dentro de la familia: frente a los sectores conservadores, resultaba mucho más factible concitar apoyo político con el argumento de los derechos de niños y niñas que con los de sus madres. Josefina Bilbao, Independiente vinculada al PDC y Ministra del Sernam ${ }^{16}$ entre 1994 y 2000, señala que "nosotros [el Gobierno], por estrategia centramos mucho más el tema en los derechos de los niños" (GÓMEZ 2010b), para así soslayar el tema implícito del alejamiento del modelo de familia tradicional. Con este marco, la iniciativa legal fue aprobada en la Cámara por 49 votos a favor, siete en contra y cuatro abstenciones. Este mismo argumento - la supremacía del interés superior del niño y su derecho a la identidad - permitió que la iniciativa fuera aprobada en el Senado por 21 votos a favor y ocho en contra, con la indicación de que se mantuviera una distinción nominal entre hijos matrimoniales y no matrimoniales. Esta distinción, que no tiene efectos en términos de derechos, fue una forma de permitir que los Senadores y Senadoras que habían resaltado los posibles efectos de la ley sobre la importancia simbólica del matrimonio - entre ellos, miembros del PDC - aprobaran la ley.

Pese a todo, hubo diputados, particularmente de la Unión Demócrata Independiente (UDI) que en los debates del tercer trámite constitucional manifestaron que el texto legal "dinamitaba" la familia y el matrimonio tradicional. Finalmente, el 8 de septiembre de 1998 la Cámara dio su aprobación al proyecto, que sería publicado el 26 de octubre de ese año en el Diario Oficial. Además de reconocer la igualdad jurídica de los nacimientos dentro y fuera del matrimonio, la nueva ley posibilita la investigación amplia de la paternidad y maternidad mediante el uso de toda clase de pruebas e incluye la presunción de paternidad o maternidad en caso de negativa injustificada de una de las partes a proporcionar evidencias como el ADN (esto es si, citada la parte

16 El Sernam un organismo gubernamental con rango de Ministerio creado en 1990 con el propósito específico de proponer y coordinar políticas interministeriales para promover la equidad de género en Chile. 
dos veces, no concurre a la realización del examen). La patria potestad, antes reservada sólo al padre de los hijos legítimos menores de edad, fue ampliada a la madre en casos específicos, aunque el ejercicio por defecto corresponde al padre (art. 244).

Así, la ley de filiación marcó un importante hito en términos de introducir el principio de igualdad de derecho de los hijos(as), por sobre la voluntad paterna de reconocer la filiación o no. En términos de género, al consagrar la libre investigación de la paternidad, eliminó del ordenamiento legal la idea de que las consecuencias del ejercicio de la sexualidad fuera del matrimonio debían recaer en las mujeres, responsables habituales de sus frutos más visibles - los hijos. Pero por sobre todo puso en cuestión la validez normativa del matrimonio como base única para la procreación y la constitución de familias. En este sentido, los dos primeros gobiernos de la Concertación sentaron las bases ideológicas para una reforma fundamental: la introducción de la ley de divorcio.

\section{AUTONOMÍA Y FAMILIA: LEY DE DIVORCIO}

El debate sobre la nueva ley de Matrimonio Civil, ocurrido entre 1995 y 2004, presenta importantes paralelos, en términos del enfoque de este estudio, con la Ley de Filiación. Tal como en el caso de los nacimientos fuera de matrimonio, en la década de los noventa el matrimonio mismo parecía ir declinando, mientras el número de uniones consensuales y "divorcios a la chilena" esto es, nulidades matrimoniales - iba en aumento. Según cifras del INE, entre 1992 y 2002 se produjo un aumento de las parejas que conviven de un $5,7 \%$ a $8,9 \%$ y la edad media para casarse se retrasó notoriamente, pasando en los hombres de 27,5 a 30,3 años y la de las mujeres de 25 a 27,6 años (INE, 2000). Las nulidades matrimoniales, único recurso para terminar legalmente un matrimonio hasta 2004, implicaban un resquicio jurídico en el cual el matrimonio se consideraba inválido debido a vicios en su celebración, pero los hijos(as) nacidos durante su vigencia se consideraban legítimos.

Vista como el último bastión legal para la familia tradicional, la indisolubilidad del matrimonio era considerada por importantes sectores políticos como expresión de los valores que dan origen a una sociedad ordenada y estable. Por razones doctrinarias, la Iglesia Católica también se opuso activamente a la posibilidad del divorcio legal en Chile. Sin embargo, de acuerdo con encuestas hechas en la época, una mayoría de los chilenos(as) - aún aquellos que se declaraban católicos ${ }^{17}$ - se mostraba favorable a la existencia de una vía legal para disolver el matrimonio. En la práctica, numerosas parejas que se separaban de hecho y volvían a constituir familias no podían formalizarlas, debido a la existencia de un matrimonio anterior aún válido jurídicamente. De las tres iniciativas legales examinadas, ésta es la única que no se originó en el Ejecutivo, sino en una moción presentada por un grupo de Diputados, varios de ellos de la Democracia Cristiana $(\mathrm{PDC})^{18}$ y que incluía al Independiente Carlos Cantero y al RN Eugenio Munizaga, ambos vinculados a la centro-derecha.

Desde el inicio del largo debate que concluyó con la promulgación de la Ley n. 19 947, fue evidente la tensión entre las libertades personales y la familia como institución. "[En el Congreso] era muy fuerte la idea de la institución [de la familia] como anterior a las personas y del matrimonio como una institución natural, incluso anterior a la ley, basada en el llamado 'derecho natural'”, señala Mariana Aylwin, Diputada del PDC para los periodos 1994-1998 e impulsora de esta iniciativa legal (GÓMEZ 2010c). Esta tensión se reflejó en los debates desde el punto de vista de la libertad de credo - esto es, la discusión respecto de la pertinencia de aplicar el principio religioso de la indisolubilidad del matrimonio en un Estado laico -, pero también desde el punto de vista de la pertinencia de reconocer múltiples tipos de familia, más allá de aquella normativamente aceptada (que

17 Según el estudio de Carla Lehmann, "La mujer chilena hoy: trabajo, familia y valores" (LEHMANN, 1995), de alcance nacional, tres de cada cuatro chilenos(as) consideraba que la ley debería permitir el divorcio en algunos casos. Entre los católicos observantes, la proporción era de $66 \%$.

18 Moción de los diputados Isabel Allende Bussi (Partido Socialista), Mariana Aylwin Oyarzún (Democracia Cristiana), Carlos Cantero Ojeda (Independiente), Sergio Elgueta Barrientos (Democracia Cristiana), Víctor Jeame Barrueto (Partido por la Democracia, centro-izquierda), Eugenio Munizaga Rodríguez (Renovación Nacional), María Antonieta Saa (Partido por la Democracia), José Antonio Viera-Gallo Quesney (Partido Socialista), e Ignacio Walker Prieto (Democracia Cristiana). Fecha 28 de noviembre, 1995. Cuenta en Sesión 27, Legislatura 332. 
no necesariamente se ajustarían al modelo tradicional) como atinente al "bien común" de la sociedad chilena. En el análisis de los debates de la Cámara y el Senado realizados para este estudio, uno de los argumentos recurrentes para oponerse al divorcio son sus efectos sociales desintegradores, tales como el aumento de las rupturas matrimoniales, de las tasas de drogadicción, delincuencia juvenil, pobreza y otros problemas sociales. El siguiente extracto ejemplifica este tipo de argumento: "A la sociedad no le da lo mismo que la familia sea estable o no; ella no puede renunciar a su derecho a promover los valores en que se funda, y la familia es el más importante de todos. Por eso, la ley debe proteger y fomentar la estabilidad del matrimonio [...] En consecuencia, no se puede decir que el divorcio no atenta contra la estabilidad de la familia y, por ende, contra la sociedad en su conjunto" (Diputado, hombre, partido de centro-derecha (PDC). Historia de la Ley n. 19 947, p. 158. Legislatura 334, sesión 44 del 23 de Enero de 1997).

En esta interpretación, sólo la familia estableesto es, basada en el matrimonio - puede proporcionar un lugar de socialización adecuado para las futuras generaciones. Dado que la socialización de niños y niñas es una tarea fundamentalmente femenina, el argumento se refiere implícitamente al orden de género propio de la familia tradicional. Desde esta perspectiva, no sólo justifica la intervención estatal en términos de favorecer un determinado tipo de familia - que deja de ser así un espacio puramente privado -, sino incluso priorizar esta intervención por sobre los derechos y libertades de las personas; en este caso, a poner término legal al matrimonio. El divorcio - continúa el argumento - banaliza el matrimonio al hacerlo provisorio, "desechable", atentando así contra el bien común. Como señaló un Diputado: "La familia constituye un organismo natural, del cual somos componentes vivos, no señores soberanos, por lo cual no viene al caso saber lo que quieren o no los cónyuges, sino lo que a ellos exige la institución para corresponder a su alta finalidad social e individual" (hombre, partido de derecha, Historia de la Ley 19 947, p. 174. Legislatura 334, sesión 44 del 23 de Enero de 1997). Como observa Nussbaum (2000), en esta visión la intervención estatal se considera legítima porque no se la ve como constitutiva, sino como una manera de dar forma jurídica y sancionar una institución pre-política. Este marco interpretativo estaba estrechamente relacionado con la doctrina pregonada por la jerarquía de la Iglesia Católica, quien le dio un espaldarazo desde el punto de vista moral.

En contraposición a estos argumentos, quienes apoyaban la iniciativa destacaban la ficción representada por las nulidades matrimoniales $\mathrm{y}$, principalmente, la necesidad de reconocer los niveles crecientes de autonomía personal de hombres y mujeres, así como el sostenido aumento de las uniones de hecho - muchas de ellas estables pero imposibles de formalizar porque uno de los cónyuges tenía un matrimonio anterior. Días antes de que se iniciara la discusión sobre la Nueva ley de Matrimonio Civil en 1995, se había presentado en el Parlamento un proyecto para regular las uniones de hecho, el cual nunca llegó al plenario para su discusión. En el caso del divorcio, a poco de iniciado el debate se hizo evidente que había que reformular los argumentos basados en la autonomía personal para hacerlos concordantes con la protección de la estabilidad matrimonial, destacando "su carácter promatrimonio. Porque el divorcio sólo tenía sentido si uno se volvía a casar; si la gente sólo convive no tiene ni para que casarse ni para que divorciarse", indica un asesor parlamentario ${ }^{19}$. María Antonieta Saa, Diputada del Partido por la Democracia (PPD) y gestora original del proyecto, explica que este cambio argumentativo tuvo carácter estratégico: "La idea era que el matrimonio tenía un carácter esencialmente para toda la vida, pero que dada la realidad existente teníamos que avanzar en una ley y el objetivo de la ley era dar una herramienta para minimizar los costos que la familia - entendiendo por "familia" los hijos - tenía que pagar ante un ruptura.[...] Otros [Parlamentarios] teníamos la posición desde el divorcio en derecho, pero ahí tuvimos que ceder: el fin último [de la ley] era regular los efectos del rompimiento matrimonial" (GÓMEZ, 2010d).

La confrontación entre "familistas" y "divorcistas" provocó serias tensiones al interior de la Democracia Cristiana - partido clave en el equilibrio político de la Concertación -, comprometiendo incluso el éxito de la tramitación

19 Entrevista personal. El (la) informante pidió anonimato 
de la ley (BLOFIELD, 2001; HTUN, 2003). Sin embargo, en 1997 la idea de legislar fue aprobada en la Cámara por 53 votos contra 40 y pasó al Senado, donde la tramitación no sería retomada hasta $2002^{20}$. En el intertanto, en las elecciones presidenciales de 1999 el Socialista Ricardo Lagos Escobar - quien incluyera la aprobación de la Ley de Divorcio en su plataforma electoral - obtuvo la victoria en segunda vuelta por un estrecho margen $(51,3 \%)$ frente al conservador Joaquín Lavín (UDI), quien había puesto la iniciativa en entredicho ${ }^{21}$.

Mala Htun (2003) ha señalado que este largo periodo de inactividad legislativa se debió a las presiones ejercidas por la Iglesia Católica chilena, apoyada por el Vaticano, frente a un Gobierno que deseaba evitar conflictos con una Iglesia que había sido defensora de los derechos humanos y que había facilitado la transición a la democracia a fines de los noventa. Sin desconocer la importancia de esa relación, la visión de los actores destaca que ni en la Iglesia Católica ni en el Gobierno había posiciones monolíticas, y que a partir del año 2000 - al asumir Lagos la Presidencia - hubo un fuerte trabajo para acercar posiciones. Adriana del Piano, miembro del Partido por la Democracia (PPD) y Ministra del Sernam entre 2000 y 2003, destaca la labor de políticos como el socialista José Antonio Viera-Gallo (Diputado entre 1990 y 1998, Senador entre 1998 y 2006) en términos de hacer una labor de "traducción" entre los objetivos de la propuesta y la visión tradicional de la familia (GÓMEZ 2010e), en la cual las referencias a la multiplicidad de familias y a las libertades individuales - excepto en lo referido a la libertad de culto - se hicieron más y más escasas. "Mantuvimos la idea de que el matrimonio es tendencialmente indisoluble, pero incluso el Derecho Canónico contempla excepciones para la ruptura matrimonial. Lo que interesaba era resguardar los vínculos familiares

\footnotetext{
20 El 13 de marzo de 2002 se retomó la iniciativa, incluida en la convocatoria a Legislatura Extraordinaria. En el año 2003 se realizaron 18 sesiones en torno al tema, la última llevada a cabo el 16 de diciembre.

21 En la Democracia Cristiana el tema seguiría siendo polémico: en 1999 y de cara a las elecciones parlamentarias de 2001, el entonces Presidente del partido Enrique Krauss, anunció que no daría su apoyo a la plataforma de un grupo de candidatas concertacionistas - entre las cuales figuraban cinco demócratacristianas - porque incluía la ley de divorcio, generando un fuerte debate al interior del partido.
}

y proteger las relaciones entre padres e hijos", señala Viera-Gallo (GÓMEZ 2010f)

La Iglesia Católica había manifestado su oposición al divorcio legal, pero también a la ficción de las nulidades matrimoniales, por razones doctrinarias y por la desprotección en la que dejaba a mujeres y especialmente, a los hijos(as). Y, de acuerdo a los(as) entrevistados(as) para este estudio, hacia 2003 parecía aceptar la inevitabilidad de la aprobación de la ley, pero deseaba que la nueva normativa estuviera inequívocamente formulada en términos de la defensa de la familia basada en el matrimonio (GÓMEZ 2010g), entendiendo este último en términos exclusivamente heterosexuales, como la unión entre un hombre y una mujer cuyo propósito central es la procreación y la asistencia mutua ${ }^{22}$. Con ello, se excluía del debate - al menos temporalmente - la posibilidad de ampliar el concepto de matrimonio a las uniones entre personas del mismo sexo. Paradojalmente, sería un gobierno de centro-derecha el que presentaría un proyecto que hace posible la unión civil para personas del mismo sexo en 2011, bajo la administración del RN Sebastián Piñera, aunque distanciándola claramente de la idea de matrimonio.

En Septiembre de 2001 ingresó a la Comisión de Constitución, Legislación y Justicia del Senado una serie de indicaciones del poder Ejecutivo a la propuesta. El nuevo texto del gobierno mantenía el divorcio vincular; sin embargo, su eje principal estaba en la protección al matrimonio y a los hijos, a través de un sistema de mediación, con la finalidad de priorizar la recomposición del vínculo $^{23}$. La modificación del gobierno retiró el "divorcio abierto", el cual señalaba - en el proyecto aprobado en 1997 - que al haber separación de común acuerdo entre los cónyuges, el divorcio puede decretarse a los tres años de ruptura efectiva, estableciendo además que si la separación se produce por la voluntad unilateral de una de las partes, el divorcio vincular puede ser decretado por el juez a los cinco años de separación, contados desde que se constate el cese de la convivencia.

\footnotetext{
22 El matrimonio civil está definido, según el Código Civil chileno, como un contrato solemne que puede ser celebrado sólo entre un hombre y una mujer (art.102).

23 Una parte mayoritaria de estos mecanismos fue eliminada en 2008 al aprobarse la Ley n. 20286 sobre Tribunales de Familia.
} 
La propuesta del Gobierno mantuvo el plazo de tres años para decretar el divorcio cuando hay acuerdo de separación en la pareja, introduciendo la causal de "divorcio culposo" frente a hechos como infidelidad, violencia intrafamiliar, maltrato o el abandono de deberes después de iniciada la separación provisoria. En el caso de no haber acuerdo de divorcio entre los cónyuges, se reducía a cuatro años el período para disolver el vínculo, desde el momento en que se constatase la separación provisional. Se incluyeron, asimismo, algunas causales de nulidad autorizadas por el Código de Derecho Canónico de la Iglesia Católica, tales como la falta de uso de razón o del suficiente juicio o discernimiento para comprender y comprometerse con los deberes esenciales del matrimonio.

La cuestión de los tiempos de espera provocó encendidos debates en el Congreso, ya que algunos Senadores los consideraban tan excesivos que, en la práctica, invitaban a volver a las nulidades como solución para poner término al matrimonio. Para otros, en cambio, permitían la reflexión y la posibilidad de evitar la ruptura. Después de una serie de votaciones anuladas por ser empates, en una estrecha votación el 22 de Enero de 2004 el Senado acortó estos plazos a un año, en el caso del divorcio de común acuerdo, por 16 votos contra 15. En el caso del divorcio unilateral, el plazo se redujo a tres años por 17 votos contra 14. El divorcio culposo no requeriría plazo de separación previa. En esta votación, la mayoría de los votos por la reducción de los plazos corresponden a Senadores concertacionistas, mientras que en la opción por extenderlos primaron los votos del sector UDI-RN. Hubo votos de la Democracia Cristiana para ambas posturas (CHILE. CONGRESO NACIONAL DE CHILE, 2004, p. 2090-2094).

En este contexto, las referencias a la autonomía personal sólo reaparecen en el Senado en términos de libertad de culto, al proponerse (y aprobarse) una indicación por la cual se buscaba hacer que el matrimonio religioso fuera válido desde el punto de vista civil, basándose en el principio de la libertad religiosa. Incluso, durante los debates se planteó la idea de que existieran dos tipos de matrimonio entre los que los novios pudieran escoger en el momento de la ceremonia: uno que permitiera la posibilidad del divorcio en el futuro y otro que fuera absolutamente indisoluble. Esta indicación, finalmente, no fue aprobada.
La ley de divorcio fue promulgada el 7 de mayo de 2004 y entró en vigencia en Noviembre de ese mismo año. La ley aprobada aún se basa en el supuesto del matrimonio heterosexual como ideal normativo para la constitución de la familia; sin embargo, al aceptar la disolución legal del matrimonio, permite a ambos cónyuges negociar en un marco jurídico el término del vínculo, el lugar de permitir que dicha negociación permanezca en un marco extra-judicial que favorece a los miembros de la pareja que están en una posición más ventajosa. Pese a ello, la ley -y el debate que la antecedió - dio escasa atención a la cuestión de la compensación económica para el cónyuge que se ocupa de las tareas de cuidado, revelando un sesgo que todavía tiende a dejarlas en la oscuridad. En la legislación aprobada, este punto fue dejado al acuerdo de las partes o bien a la resolución del Juez, quien debe ponderar la situación financiera de cada cónyuge sin que se establezcan criterios explícitos en la legislación ${ }^{24}$.

\section{CONCLUSIONES}

El examen de los argumentos y marcos interpretativos movilizados en la discusión de las leyes sugiere que la idea de ciudadanía femenina entendida como las relaciones legalmente establecidas entre las mujeres y el Estado - está íntimamente ligada a la concepción de familia y del lugar que ésta ocupa en la idea de una sociedad bien ordenada o del "bien común". Desde el punto de vista político-partidista, los partidos políticos chilenos carecen de un discurso oficial acerca de la familia y los temas valóricos que sea parte integral de la plataforma partidaria y frente a temas como matrimonio, familia, sexualidad y reproducción dan a sus parlamentarios libertad de acción para votar de acuerdo a convicciones personales. Sin embargo, los parlamentarios(as) de partidos más cercanos a la derecha - bloque UDI-RN y un ala de la Democracia Cristiana tienden a promover el retorno a los valores

\footnotetext{
24 La aprobación de la ley tampoco produjo los resultados apocalípticos que sus detractores anunciaban: desde 2004 , el número de matrimonios ha aumentado levemente - de 54 122 en 2005 a 56357 al 2010 -, mientras que el de divorcios alcanzó su número máximo para la década en 2009, con 53 558 causas - muchas de ellas posiblemente debidas a situaciones no resueltas antes de la promulgación de la ley. Esta interpretación, con todo, está fuera de los objetivos de este estudio.
} 
tradicionales, basados en la idea de estabilidad social y familia "bien constituida", aunque no hay una correlación significativa y se verifican incluso alianzas inter-partidarias para promover ciertos resultados legislativos (véase también Blofield (2002) y Htun (2003)).

No obstante, la manutención de la familia tradicional, basada en el matrimonio, como terreno privilegiado para la negociación política, más allá de las mayorías partidarias existentes en el Parlamento, señala la fuerza ideológica de este constructo como un factor considerado clave para la estabilidad social, tanto desde el punto de vista biológico - el trabajo de reproducción y cuidado - como cultural. Como ha señalado Vogel (1998), la regulación estatal de las relaciones de género en este caso, a través de la familia - es particularmente visible en la idea de orden público; esto es, la regulación de patrones de relaciones entre miembros de la comunidad política mediante la aplicación de la ley. El significado del orden público, en esta perspectiva, está cercanamente relacionado con definiciones de relaciones familiares, reproducción, sexualidad e identidades de género o, más claramente, con un modelo normativo que el Estado privilegia a través de la legislación y las políticas públicas. Así, señala Vogel, el significado de género y orden público están entrelazados en un círculo en el cual uno presupone al otro (idem, p. 38).

Por otra parte, como hemos señalado más arriba y siguiendo a Martha Fineman (2004), la revisión de la idea de familia implica revisar también su carácter privado y la distribución de tareas de cuidado dentro de la sociedad. El cambio es resistido porque implica des-privatizar la responsabilidad por el cuidado y re-examinar nuestras ideas sobre dependencia y derechos individuales, incluyendo la dependencia constitutiva de la propia condición humana, de carácter inescapable y universal. Pero también implica re-examinar la idea de complementariedad entre los sexos - biológico-reproductiva, afectiva y de funciones - sobre la cual se construye la familia tradicional. Esto podría explicar la resistencia a ampliar el concepto de familia a una estructura que no esté basada exclusivamente en el matrimonio, así como a aceptar el matrimonio entre personas del mismo sexo. Si se modifica la estructura de la familia, la célula fundamental de la sociedad, resultará necesario revisar gran parte de los arreglos institucionales vigentes en el Estado y el mercado.

Aquí radica, creemos, la fuerza política e ideológica de la familia tradicional. Ello no implica desconocer que las leyes examinadas constituyen avances significativos en el camino por una mayor equidad de género o por el reconocimiento de la pluralidad de formas familiares. Del mismo modo, tampoco implica argumentar que la familia no resulta central para la sociedad: por el contrario, reconocemos la importancia radical que ella tiene para la manutención de cualquier orden social. Se trata, sí, de reconocer que por esta misma razón, debe reconocerse, desde el Estado y las políticas públicas, la pluralidad de formas en que ésta puede organizarse para promover espacios de libertad personal y autonomía para cada uno de sus miembros, de manera tal que la familia constituya realmente un espacio en el cual las personas puedan desarrollar su potencial humano sin importar su sexo o edad. Desde esta perspectiva, la evidencia presentada en este artículo confirma la hipótesis de que en Chile los derechos de las mujeres como individuos y ciudadanas aún están condicionados a fines ulteriores, como la provisión de cuidado y socialización adecuados para los hijos, la manutención del patrimonio familiar o una noción determinada de estabilidad social. Ello, argumentamos, ofrece algunas claves para entender ciertos procesos legislativos en el área de género y familia, desde la perspectiva de hacer efectivos los derechos de ciudadanía para las mujeres y otros grupos sociales. Esta última tarea requeriría ampliar el concepto de familia y los derechos asociados a cada uno de sus miembros de una manera que refleje de la multiplicidad de formas de hacer familia que prevalecen en la sociedad.

Verónica Edith Gómez Urrutia (gomezver@gmail.com) é Doutora em Gender Studies pela University of Sussex (Reino Unido) e Professora de Ciência Política na Universidad de Talca. 


\section{REFERÊNCIAS BIBLIOGRÁFICAS}

ARRIAGADA，I. 2007. Transformaciones familiares y políticas de bienestar en América Latina. In: (coord.). Familias y políticas públicas en América Latina: una historia de desencuentros. Santiago: CEPAL.

ARAUJO, K.; GUZMÁN, V. \& MAURO, A. 2000. El surgimiento de la violencia doméstica como problema público y objeto de políticas. Revista de la Cepal, Santiago, n. 70, p. 133145, Abr. Disponível em: http://www.cem.cl/ pdf/domestic_araujo.pdf. Acesso em: 15.mar.2013.

BLOFIELD, M. 2001. The Politics of "Moral Sin": A Study of Abortion and Divorce in Catholic Chile since 1990. Santiago: FLACSO.

2002. Guerra santa. La izquierda y la derecha frente a temas valóricos en el Chile democrático. In: DÁVILA, M. \& FUENTES, C. (coords.). Promesas de cambio: izquierda y derecha en el Chile contemporáneo. Santiago: Universitaria.

FINEMAN, M. 2004. The Autonomy Myth. A Theory of Dependency. New York: The New Press.

GÓMEZ, V. 2010a. Entrevista pessoal com Adriana Muñoz, Deputada do PPD, realizada em Santiago, 6 de setembro.

2010b. Entrevista pessoal com Josefina Bilbao, vinculada ao PDC e Ministra do Sernam entre 1994 e 2000, realizada em Santiago, 25 de março.

2010c. Entrevista pessoal com Mariana Aylwin, Deputada do PDC entre 1994 e 1998, realizada em Santiago, 13 de janeiro.

2010d. Entrevista pessoal com María Antonieta Saa, Deputada do PPD, realizada em Santiago, 30 de abril.

2010e. Entrevista pessoal com José Antonio Viera-Gallo, Deputado entre 1990 e 1998 e Senador entre 1998 e 2006 pelo Partido Socialista, realizada em Santiago, 9 de abril.

.2010f. Entrevista pessoal com José Antonio Viera-Gallo, realizada em Santiago, 3 de junho.

2010g. Entrevista pessoal com Jorge del Picó, Acessor do Ministerio de Justicia entre
2000 e 2003, realizada em Talca, 26 de novembro.

HAAS, L. 1998. The Effects of Structure on Policymaking: An Examination of Women's Rights in Chile, 1990-1998. Trabalho apresentado no XXI Encuentro Anual de la Asociación de Estudios Latinoamericanos (LASA), realizado em Chicago, de 24 a 26 de setembro. Digit.

HTUN, M. 2003. Sex and the State. Cambridge (UK): Cambridge University.

INFANTE, R. \& SUNKEL, G. 2004. Chile: trabajo decente y calidad de vida familiar, 1990-2000. Santiago: Oficina Internacional del Trabajo.

JELIN, E. 2007. Las familias latinoamericanas en el marco de las transformaciones globales. In: ARRIAGADA, I. (coord.). Familias y políticas públicas en América Latina: una historia de desencuentros. Santiago: CEPAL.

KERSHAW, P. 2006. Care Fair: Choice, Duty, and the Distribution of Care. Social Politics, Oxford, v. 13, n. 3, p. 341-371, Autumn.

LEHMANN, C. 1995. La mujer chilena hoy: trabajo, familia y valores. Revista de Estudios Públicos, Santiago, n. 60, p. 99-202. Disponível em: http://www.cepchile.cl/dms/ archivo_1227_3092/rev60_CLehmann.pdf. Acesso em: 16.mar.2013.

MAINWARING, S. \& SCULLY, T. 1995. Building Democratic Institutions: Party Systems in Latin America. Stanford: Stanford University.

MAURO, A. \& YÁÑEZ, S. 2005. Trayectorias laborales y previsión social en Chile en un contexto de flexibilidad. Santiago: CEM.

MILOSAVLJEVIC, V. 2007. Estadísticas para la equidad de género. Magnitudes y tendencias. Santiago: CEPAL.

MONTAÑO, S. 2007. El sueño de las mujeres: democracia en la familia. In: ARRIAGADA, I. (coord.). Familias y políticas públicas en América Latina: una historia de desencuentros. Santiago: CEPAL.

NUSSBAUM, M. 2000. Women and Human Development. Cambridge (UK): Cambridge University. 
PÉREZ SERRANO, G. 1998. Investigación cualitativa. Retos e interrogantes. V. I: Métodos. Madrid: La Muralla.

PONCE DE LEÓN, M.; RENGIFO, F. \& SERRANO, S. 2006. La "pequeña república". La familia en formación del estado nacional, 1850-1929. In: VALENZUELA, S.; TIRONI, E. \& SCULLY, T. (coord.). El eslabón perdido. Familia, modernización y bienestar en Chile. Santiago: Taurus.

ROSEMBLATT, K. 2000. Gendered Compromises: Political Cultures and the State in Chile 19201950. Chapel Hill: University of North Carolina.

ROZAS, F. 1989. Consideraciones sobre la modificaciones que la Ley 18.802 introduce al Código Civil. Revista Chilena de Derecho, Santiago, v. 16, n. 1, p. 99-110. Disponível em: http://dialnet.unirioja.es/descarga/articulo/ 2649637.pdf. Acesso em: 16.mar.2013.

SELAMÉ, T. 2004. Mujeres, brechas de equidad y mercado de trabajo, Chile. Santiago: OIT.

TODARO, R. 2006. ¿Flexibilidad laboral o precarización? El debate sobre la reproducción social. In: LÓPEZ, C. M.; ESPINO, A.; TODARO, R. \& SANCHÍS, N. (coords.). América Latina, un debate pendiente.
Montevideo: Repem. Disponível em: http:// www.cem.cl/pdf/libro_america_latina.pdf. Acesso em: 15.mar.2013.

VALDÉS, T. 1998. Entre la modernización y la equidad: mujeres, mundo privado y familias. In: TOLOZA, C. \& LAHERA, E. (coords.). Chile en los noventa. Santiago: Presidencia de la República.

VALDÉS, X. 2007a. Notas sobre la metamorfosis de la familia en Chile. Documento preparado para a reunião de especialistas "Futuro de las familias y desafíos para las políticas públicas", CEPAL-UNFPA, realizada em Santiago, de 22 a 23 de novembro.

2007b. La vida en común. Transformaciones familiares en Chile y el medio rural en la segunda mitad del siglo XX. Santiago: LOM.

VALENZUELA, J. S.; TIRONI, E. \& SCULLY, T. (coords.). 2006. El eslabón perdido. Familia, modernización y bienestar en Chile. Santiago: Taurus.

VOGEL, U. 1998. The State and the Making of Gender: Some Historical Legacies. In: RANDALL, V. \& WAYLEN, G. (eds.). Gender, Politics and the State. London: Routledge.

\section{OUTRAS FONTES}

CHILE. 1993. Mensaje 198-326 de S.E. el Presidente de la República con el que inicia un proyecto de ley que modifica el Código Civil y otros cuerpos legales en materia de filiación. Santiago, 22.jul.

CHILE. CONGRESO NACIONAL DE CHILE. 1998a. Historia de la Ley 19.335. Valparaíso: Biblioteca del Congreso.

1998b. História de la Ley 19.585. Valparaíso: Biblioteca del Congreso.

2004. Historia de la Ley 19.947. Valparaíso: Biblioteca del Congreso.

CHILE. MIDEPLAN. 2003. Resultados de la IX Encuesta de Caracterización Socioeconómica Nacional. Perfil de la Mujer Adulta Mayor. Santiago: Mideplan.

2009. Resultados de la XI Encuesta de Caracterización Socioeconómica Nacional.
Educación. Santiago: Mideplan. Disponível em: http://www.mideplan.gob.cl/casen2009/ casen educacion.pdf. Acesso em: 15.mar.2013.

CHILE. MINISTERIO DE EDUCACIÓN. 2002. Compendio de Información Estadística 2000. Santiago: Ministerio de Educación.

CHILE. REGISTRO CIVIL. 2011. Inscripciones de Registro Civil. Santiago: Servicio de Registro Civil. Disponível em: http:// www.registrocivil.cl/Servicios/Estadisticas/ Archivos/InscripcionesRCivil/inscrip.html. Acesso em: 15.mar.2013.

CHILE. SERNAM. 1996. Maternidad. Tendencias y variables influyentes. Santiago: Sernam. Disponível em: http://estudios. sernam.cl/documentos/?eMTQ2NDc3MQ==Maternidad: Tendencias y Variables Influyentes. Acesso em: 17.mar.2013. 
INE. 2000. Enfoques estadísticos: matrimonio. Boletín Informativo del Instituto Nacional de Estadísticas de Chile, n. 6, Jul.
PNUD. 2010. Desarrollo Humano en Chile: género, los desafíos de la igualdad. Santiago de Chile: PNUD. 

2004)

\section{Verónica Edith Gómez Urrutia}

This article examines debates referring to three legal reforms that took place between 1990 and 2004 and which had fundamental results regarding the legal configuration of the Chilean family. Taking legislative discourse as the basis of our analysis, I argue that it took a long and complex process of political negotiation to build a broader concept of what family is. The process brought notions of gender, individual autonomy and what constitutes a "good society" into play. The results of this process, if on the one hand signifying a move forward in terms of gender equality, also favor the traditional model of family- dual parent, based on heterosexual marriage - as the family form recognized by the State. In this regard, women's citizenship rights continue to be subordinate to traditional gender roles, in which women are seen as responsible for caring for the vulnerable and for sustaining the family as a site of social reproduction Methodologically speaking, we carry out a a qualitative analysis of official records of Parliamentary debates for the three laws under discussion. Analysis has been complemented by in-depth interviews with legislators and members of the Executive who took part in debates within the National Congress.

KEYWORDS: Family; Gender; Chilean Law; Women's Rights. 
LE DIVORCE À LA CHILIENNE: LA FAMILLE, LE GENRE ET LA CITOYENNETÉ AU CHILI (1990-2004)

\section{Verónica Edith Gómez Urrutia}

L'article vérifie les débats mentionnés liés à trois réformes légales qui ont des résultats fondamentaux pour la configuration légale de la famille au Chili, qui ont eu lieu entre 1990 et 2004. En ayant comme base l'analyse du discours législatif, j'argumente que, pour élargir le concept de " famille », d'une manière dont la multiplicité de réalités qu'il peut représenter soit reconnue, il a fallu un long et complexe processus de négotiation politique où ont été considérées des conceptions de genre, l'autonomie individuelle, et ce qui constitue une « bonne société ». Malgré le fait d'être considérés comme une évolution par rapport à l'égalité de genre, les résultats de ce processus favorisent encore le modèle traditionnel familial - biparentale, basée sur le matrimoine hétérosexuel - comme le type de famille a être protégée par l'État. Ainsi, les droits des femmes autant que citoyennes, sont subordonnés aux rôles de genre traditionnels, puisqu'elles sont encore vues comme les responsables par le soin de personnes en situation de vulnérabilité et par l'entretien de la famille autant qu'un espace de reproduction sociale. Méthodologiquement, le travail est basé sur une analyse qualitative des enregistrements officiels des débats dans le Parlement pour les trois lois vérifiées. Cet analyse a été complémentée avec des interviews en profondeur avec des législateurs et membres du Pouvoir Exécutif qui ont participé des débats dans le Congrès National.

MOTS-CLÉS: famille; genre; législation chilienne; droits de la femme. 